\title{
An analytic hierarchy process for quality action researches in education
}

\author{
Alvin Bersabal Barcelona \\ Senior High School Department, UST- Angelicum College, Philippines
}

\begin{tabular}{l} 
Article Info \\
\hline Article history: \\
Received Mar 29, 2020 \\
Revised Jun 30, 2020 \\
Accepted Jul 20, 2020 \\
\hline
\end{tabular}

Keywords:

Action research

Analytic hierarchy process

Education

Research authorities

Teacher

\begin{abstract}
Teachers are expected to engage in the praxis of educational reform, and one of the resurgent interests in the field of education is the conduct of action researches. In the Philippines and in many parts of the world, teachers are encouraged to perpetuate a culture of conducting action researches to improve the teaching and learning process. Considering the scant literature towards evaluation criteria for quality action researches, this exploratorysequential mixed method study aims to determine the qualities that research experts perceive to be useful in evaluating action researches. Using Analytic Hierarchy Process, which is a multiple decision-making algorithm, research experts asserted that among the identified evaluation criteria, quality action researches should underscore its contribution to theory and practice, and require actionability and reflexivity among researchers and participants. The findings of this study may be of considerable interest and use to teachers, research authorities, and organizations who would like to ensure that teachers produce quality action research to improve educational practices.
\end{abstract}

This is an open access article under the $\underline{C C B Y-S A}$ license.

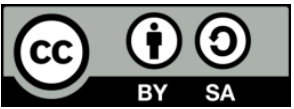

\section{Corresponding Author:}

Alvin Bersabal Barcelona,

Senior High School Department, UST Angelicum College,

112 M.J. Cuenco Street, Quezon City, Philippines.

Email: barcelona.spain0914@gmail.com

\section{INTRODUCTION}

There is a resurgent interest in action research particularly in the field of education nowadays. Conducting quality researches does not only inform teaching and learning but empowers teachers to become more reflective of their roles and responsibilities in the clasroom, and for schools to improve the delivery of quality education for the students. It is for this reason that teachers, if not required, are encouraged to conduct researches which are relevant to their field of teaching in the form of action research.

Action research is a cyclical process that may be used to improve instructional practice, assessment tools, and student outcomes with focus on specific problems which usually take place in the natural setting of a classroom, laboratory or school [1]. This is the main reason why Lytle \& Smith [2] use the term teacher research synonymously with action research where teachers are situated as learners in order to change and improve their teaching [3]. It is not only a scientific way of producing knowledge but a systematic way of solving problems [4]. The advantage of this kind of research compared to the other kinds of traditional researches, aside from its simplicity, is its potential to create meaningful and authentic change for those involved, whether in a classroom or community [5]. In the Philippines, teachers of private and public sectors are enjoined to conduct action researches which can improve their teaching practices and learning outcomes of students. 
The term "quality" as operationally used in this study is defined as the goodness of an action research based on some standards. Ensuring that teachers conduct quality action researches is of great importance. While action research is not a recent approach to research and that it has been widely used in various disciplines, there is an immense literature gap regarding on how to evaluate action researches in education, and what criteria are relevant to use. According to Meyer [6], the fact that action research arises from a different epistemological background means that it cannot be judged using the same criteria as other research approaches. Moreover, the fact that there is no convention for evaluating action researches [7] particularly in education necessitates collective effort to identify criteria which can be used evaluate action researches made by teachers. In fact, one of the implications in the study of Rowell, et. al [8] reveals that one of the challenges which is associated with action research is contribution to quality and rigor in critiquing action research. Teachers need further support and clarification in action research [9] most notably because evaluation of researches is usually set by the examining authority in different academic institutions in the Philippines, and this process from identification of criteria to the actual evaluation of action researches may be subjected to biased and poor judgment, if not done correctly and conscientiously.

One of the notable literatures related to the present study is what Zuber- Skerrit \& Fletcher [10] presented as quality criteria in action research theses in social sciences. According to the researchers, a quality action research presents a critical analysis of a well-defined problem which raises a "thematic concern" referred to as a major issue in community development. Also, the "quality" comes with the use of an appropriate methodology which can advance knowledge in the field. It provides convincing evidence for the claimed knowledge and demonstrates critical reflection which can contribute to transforming knowledge and practices. In addition, valid and quality researches emerge from the reflection of teachers on their work [11].

Moreover, Feldman [12] criticized the principles of quality action research proposed by Heikkinen, Huttunen and Syrjala. According to him, historical continuity, reflexivity and dialectics, workability and evocativeness may be insufficient criteria because these may only applicable to the research report and not to the action research itself. While he thought that reflexivity and dialectics may be used as criteria, he added that action researches should include clear and detailed descriptions of how and why the data were collected, provide clear and detailed descriptions of how their narratives were constructed from the data, present an explanation or theory of why it works. Moreover, he averred that it is when the action researchers pay attention to validity of their work that their action researches can have good quality.

The purpose of this paper is to determine the preferred evaluation criteria for action researches in education using the Analytic Hierarchy Process (AHP) by experts. This method is a multiple decisionmaking method that models decision-making processes mathematically and are used to solve complex problems [13]. Using AHP, this research intends to identify, rank, and determine the weight of the criteria which research experts perceived as critical in appraising action researches conducted by teachers. This study is of great relevance since evaluation of action researches made by teachers does not only improve the delivery of education, but it used nowadays to appraise teachers' dedication and commitment for professional growth.

\section{RESEARCH METHOD}

This study employed an exploratory- sequential mixed method design. The purpose of an exploratory- sequential mixed methods design involves the procedure of first gathering qualitative data to explore a phenomenon, and then collecting quantitative data to explain relationships found in the qualitative data [14]. The researcher analyzed documents particularly rubrics used in assessing action researches by experts and organizations, reviewed literature about action researches, and interviewed field experts to come up with evaluation criteria. These were then tested and further analyzed using AHP to determine the criteria weights as evaluated by the research experts.

The main respondents of this study were five experts in the field of research and evaluation of who were purposively selected by the researcher. In selecting respondents, four criteria were considered which are their academic preparation, years in the teaching profession, and experiences in writing and evaluating researches. All five experts are Ph.D. in Educational Research and Evaluation candidates, have at least 10 years of teaching experience, have published researches both in local and international journals, and were invited to evaluate researches and journals a number of times in the past. Figure 1 describes process flow of this research. 


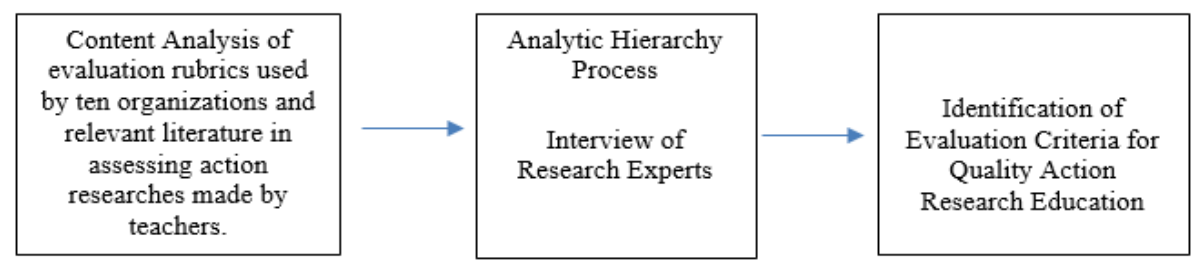

Figure 1. Process flow of this research

\subsection{Collection of qualitative data}

The first phase of data gathering was the collection and analysis of qualitative data. The researcher conducted content analysis of evaluation rubrics used by ten (10) organizations in assessing action researches made by teachers, interviewed research experts, and reviewed relevant literature. The data obtained from multiple sources of data were validated by two experts who both have PhD. in Education degrees.

\subsection{Collection of quantitative data using analytic hierarchy process}

After finalizing the criteria for the evaluation of educational action researches, it was subjected to AHP. This is a multi-criteria programming technique for decision making in complex environments in which many variables or criteria are considered in the prioritization and selection of alternatives or projects such as evaluation criteria for educational action researchers where there are a number of considerations which need to take into account. AHP transforms the comparisons, which are most often empirical, into numerical values which are further processed and compared. The weight of each factor allows the assessment of each one of the elements inside the defined hierarchy. This capability of converting empirical data into mathematical models is the main distinctive contribution of the AHP technique when contrasted with other comparing techniques [15].

The main advantage of AHP is its ability to rank choices in the order of their effectiveness in meeting conflicting objectives [16] which is suitable to the purpose of this study which is to determine evaluation criteria for educational action researches made by teachers. Moreover, AHP is appropriate to people are working with problems involving human perceptions and judgment whose resolutions have longterm repercussions [16] and allows some small inconsistencies in the judgment because it recognizes that human perception is not always consistent. In addition to this, the implementation of AHP is based on the experience and knowledge of the experts or users to determine the factors affecting the decision process [17]. In this study, after the criteria in evaluating action researches were identified based on the qualitative analysis of data, the magnitude or weight of each criterion were determined by comparing two criteria at a time. AHP requires decision makers to carry out simple pairwaise comparison judgments [18]. This stems from the fact that AHP adheres the fact that the magnitude of criteria may not be equal as preferred by various evaluators or experts. In pairwise comparison, the respondents were asked to use the AHP scale that follows in determining which of the criteria has more merit for them as shown in Table 1.

Table 1 . The analytic hierarchy process (AHP) scale

\begin{tabular}{ccc}
\hline Intensity of Importance & Short Descriptors & Interpretation \\
\hline 1 & Equal & The two criteria contribute equally to the objective \\
3 & Moderate & Experiences and judgments slightly favor one over the other. \\
7 & Strong & $\begin{array}{c}\text { Experiences and judgments strongly favor one over the other } \\
\text { Experiences and judgments very strongly favor one over } \\
\text { the other where its importance is demonstrated in practice. }\end{array}$ \\
9 & Very Strong & The evidence favoring one over the other is of the highest \\
possible validity.
\end{tabular}

\section{RESULTS AND DISCUSSION}

After conducting content analysis of the evaluation rubrics from ten research experts and organizations, and themes surfaced from interviews, seven research criteria emerged. The most comprehensive summary of evaluation criteria for action researches which can encapsulate the results of the qualitative analysis done by the researcher can be compared to what Bradbury-Huang [19] presented as quality criteria for action researches. For the purpose of clarity and proof of literature underpinnings, these seven criteria were adopted in this study. These criteria were compared and analyzed further by the research experts to determine its weight using the Analytic Hierarchy Process. 


\subsection{Well-articulated objectives}

Quality action research has clear objectives which guided the entire work from the beginning until the end. This means that a well-defined and strong purpose is articulated from the beginning of the study which gives direction to the action research process. At the end of the study, the action plan and the impact of the involvement of teachers in the process can be asserted as the realization of the stated objectives.

\subsection{Incorporate partnership and cooperation among stakeholders}

Quality action research encourages participation among stakeholders from mere consultation with them and to the extent of engaging them as co-researchers. The identified and raised problems in action researches may directly affect the stakeholders such as the students, teachers, administrators, parents, and the whole school community. It is essential to encourage them to be actively engage in every step of the research process as they help the researcher in the identification of the problem, design of the investigation, and in the implementation and assessment of the action plan. In fact, Hart \& Bond as cited in Deery [20] asserted that the nature and degree of democratic collaboration are crucial to the success of the action research process.

\subsection{Contribution to theory and practice}

Quality action research does not only contribute to the action research literature but provides inputs to theories and practices in education. The contribution to theory and practice is simply the impetus which will help change and improve the present problematic situation in the classroom or school setting. The aim is for improvement within the context and situation within which the study is conducted in the key priority of the action. With this, Frogatt \& Hockley [21] seconded that this kind of methodology bridges the gap between theory and practice where teachers are challenged to leverage their insider knowledge to change and improve classroom practices [22].

\subsection{Use of appropriate and accurate methods and processes}

Quality action research makes use of appropriate and accurate methods and processes which help the researchers in realizing the objectives of the study. Just like traditional scientific researches, the paradigm of action researches needs to make use of accurate methodologies. According to Bradburry and Reason as cited in Skerrit and Fletcher [10], drawing on and integrating diverse ways of knowing and using different methodologies appropriately and creatively in the context of action research is an indispensable expectation to this kind of research.

\subsection{Requires actionability}

Findings generated from action research provide specific actions in response to the problem raised in the study. As posited by Cain [2], research and action are integrated in a series of flexible cycles. The planning, introduction, and implementation of the "action" are to address the raised problem is needed to bring about positive change.

\subsection{Requires reflexivity among action researchers}

The action research becomes an impetus to make the researcher takes a personal, involved, and selfcritical stance about their role in from the conceptualization of the problem and in designing action to promote change and improvement. Giddens as cited in Robertson [23] described reflexibity as selfawareness. These quality criteria can be demonstrated by action researchers by presenting how their involvement in the research process has made them more aware of their contribution to the problem and transformed them to improve their roles as educators to address the problem. Moreover, as researchers, they should ardently show how their engagement in the process of action research has penetrated in their personal life and work, and how their social world affects their disposition and action leading to the ariculation of the problems and formulation of solutions.

\subsection{Significance beyond immediate context}

Action researches of good quality are not only relevant to the immediate context but extend to bigger systems and communities where findings can be of great use. While the priority of action researches is to test and recommend possible solutions to problems of immediate context such as those affecting a specific classroom setting, its significance should go beyond this classroom and should benefit other classrooms of almost the same setting or bigger entity where this classroom is experiencing academic challenges. This is what Huang- Bradburry [19] described as the meaning and support of action research to the flourishing of people, communities, and wider ecology. 
Table 2 summarizes the derived weights of each evaluation criterion which is the result of the Analytic Hierarchy Process pairwise comparison. Among the seven evaluation criteria, the criterion contribution to theory and practice obtained the highest mean weight of $24.64 \%$ with three experts perceiving it as the most important aspect to look into action researches conducted by teachers. It is followed by the criterion where action research should require actionability with a mean weight of $18.50 \%$ with one expert believing that it is the most important criterion. The third highest criterion is that action research requires reflexivity among action researchers with a mean weight of 16.60 with one expert believing it is the most important evaluation criterion for action research.

Table 2. AHP derived weights of evaluation criteria for action research

\begin{tabular}{|c|c|c|c|c|c|c|c|}
\hline \multirow{2}{*}{ Criteria } & \multicolumn{5}{|c|}{ Experts } & \multirow{2}{*}{ Mean } & \multirow{2}{*}{ Rank } \\
\hline & 1 & 2 & 3 & 4 & 5 & & \\
\hline 1. Well -articulated Objectives & 2.60 & 3.8 & 2.5 & 5.5 & 10.7 & 5.04 & 7 \\
\hline $\begin{array}{l}\text { 2. Incorporate partnership and cooperation } \\
\text { among stakeholders }\end{array}$ & 13.50 & 3.5 & 3.6 & 3.5 & 18.8 & 8.56 & 6 \\
\hline 3. Contribution to theory and practice & 8.20 & 36.9 & 19.4 & 28.3 & 30.4 & 24.64 & 1 \\
\hline $\begin{array}{l}\text { 4. Use of appropriate and accurate } \\
\text { methods and processes }\end{array}$ & 8.00 & 13.1 & 15.8 & 19.0 & 7.0 & 12.58 & 5 \\
\hline 5. Requires actionability & 43.20 & 6.1 & 11.4 & 13.0 & 18.8 & 18.50 & 2 \\
\hline $\begin{array}{l}\text { 6. Requires reflexivity among action } \\
\text { researchers }\end{array}$ & 2.10 & 25.7 & 32.3 & 13.2 & 9.8 & 16.60 & 3 \\
\hline 7. Significance beyond immediate context & 22.40 & 10.9 & 15 & 17.5 & 4.5 & 14.08 & 4 \\
\hline AHP Consistency Ratio & 0.098 & .098 & .084 & .086 & .093 & & \\
\hline
\end{tabular}

While all criteria are proven to have wide applicability in evaluating action researches in education based on the first phase of data collection which is content analysis of evaluation rubrics used by different organizations, the criteria significance beyond immediate context $(14.06 \%)$, use of appropriate and accurate methods, and processes (12.58\%), incorporate partnership and cooperation among stakeholders $(8.56 \%)$ and well-articulated objectives $(5.04 \%)$ were given less priorities by the research experts. Since all the consistency ratios are less than $10 \%$, the inconsistencies of the subjective judgments of the experts are acceptable.

In order to enrich and elucidate the data obtained from AHP pairwise comparisons made by experts, interview data were considered. According to the first expert (E1), "Since action research has many different frameworks and paradigms, some evaluation criteria may not be explicitly evident in the report such as partnership and cooperation among stakeholders because of issues of time and resources or may not be able to address its significance beyond immediate context because of lack of generalizability power. Instead, what must be ensured is its contribution to theory and practice in education which is to improve educational practice. This is supported by E5 when he posited that the criterion contribution to theory and practice is the ultimate goal of conducting researchers of whatever forms. It is likened to an umbrella criterion that covers the other identified criteria. These ideas support that the very essence of action research in education is to provide practitioners with new knowledge and understanding on how to improve practices by resolving significant problems in classrooms and schools [24]. In action research, teachers prescribe a recommendation written and prepared by them which they believed are practical solutions to their problems [25].

E1 who predominantly gave the highest priority weight on the criterion requires actionability asserted that action should be an intrinsic part of the researcher(s) and participants which is seen through the action taken to look at one' s own practice or situation to seek out aspects in teaching to improve practice or situation. According to the expert, when action research requires actionability, it does not only describe and require the final action prescribed to solve the raised problem, but it highlights the series of critical and careful actions taken by the researchers and those who are involved in every step of the research process to realize the objectives of the study. This disposition supports that quality action researches not only inform participants and audience, but encourages them to carry out actions to improve their present condition as change agents [19] and these actions are substantive located through a research procedure, disciplined by enquiry, and a personal attempt to understand, improve, and reform practice [26]. This makes the "action" in action research challenging to define, measure, and achieve [27].

Requiring reflexivity among action researchers and participants is also given higher priorities by the experts among others. According to E3, quality action researches in education should be informed by reflexive thinking and investigation, a form of self-study of one's own roles and stance of the problem and how his present performance can be improved to change the situation for the better. The expert stressed that as teacher-researcher, one needs to unpack the very self in the practice of teaching, engage in critical and careful thinking to self-evaluate current practice. Hong \& Lawrence [28] renounced the same when they

An analytic hierarchy process for quality action researches in education (Alvin Bersabal Barcelona) 
contend that self-reflection is important in action research as it is a powerful way to know more about the self in research and practice a reflexive pedagogy which can help teachers closely examine current practices and spearhead change as teacher- leaders. By being reflexive in their approach, teachers are empowered when they are able to collect and use data in making informed decisions about their own schools and classrooms, Book; Fueyo \& Koorland; Hensen; as cited in Hine [24]. This is true when teachers exercise their individual talents, experiences and creative ideas within the classroom; they become empowered to make changes related to teaching and learning. Also, the self-reflexivity is seen in a spiral approach which consists of a planning, implementing action, reflecting and repeating the process as necessary [29]. This makes reflection a complex process which demands the role of values and existential knowledge in education among teachers [30] and researchers should continuously reflect and do self-evaluation which should be intentional and systematic [31].

\section{CONCLUSION}

The proclivity of teachers to conduct researches for personal and professional growth is very evident at present as action researches continue to score and flourish. Hence, the present research focused on articulating the qualities of action researches perceived to be meaningful and critical as perceived by experts. With the complexity and variations in the framework, theoretical underpinnings, and contextual considerations, the researcher recognized that quality in action research is multifaceted, and that teachers, evaluators, and organizations need to critically select what qualities should be prioritized.

The qualitative empirical data collected in the first phase of this exploratory- sequential mixed method design study has proven that there are many possible quality criteria which can be used in evaluating action researchers made by teachers such as what Brandburry-Huang summarized in her paper. The use of the Analytic Hierarchy Process in the second phase of data gathering and analysis facilitated, clarified, and refined which of these criteria may be given more consideration and greater weights such as the criteria of (1) contribution to theory and practice, (2) requires actionability, and (3) reflexivity among researchers.

The contribution of action research to educational theory and practice should always be foregrounded regardless of research objectives, context, and methods. This means that the action researcher is expected to impress the quality of his/her work by underscoring clearly how the entire process can be meaningful by expanding existing knowledge and improve current practice. Moreover, the action in action research brings quality when it is based on the systematic process of research and is taken seriously and effectively to improve the teaching and learning condition. Also, quality of reflexivity among action researchers cannot be taken for granted. Teachers should engage in reflective teaching habitually, and find ways on how their roles can be modified and improved to espouse change and solution to pressing problems inside the classroom and within the school.

While qualities in action research continue to evolve and change in the future, the Analytic Hierarchy Process has proven that it can be used to help teachers, practitioners, and evaluators to select and make complex decisions in dividing priorities among seemingly equal valued options concerning research and evaluation. The findings of this study may be of considerable interest to those individuals and organizations wishing to evaluate the merit and quality of action researches completed by teachers.

\section{REFERENCES}

[1] P. Lari, A. Rose, J. Ernst, A. Clark, D. Kelly, and V. De Luca, "Premiere pd: Action research," Technology and Engineering Teacher, vol. 79, no. 2, pp. 23-27, 2019.

[2] T. Cain, "The characteristics of action research in music education," B. J. Music. Ed., vol. 25, no. 3, pp. 283-313, 2008.

[3] M. McGlinn, "Action research and systematic, intentional change in teaching practice," Review of Research in Education, vol. 43, no. 1, pp 163-196, 2019.

[4] C. Yigit and B. Bagceci, "Teachers' opinions regarding the usage of action research in professional development," Journal of Education and Trining Studies, vol. 5, no. 2, pp. 243-252, 2017.

[5] M. Vaughan, M. Boerun, and L. Whitehead, "Action research in doctoral coursework: Perceptions of independent research experiences," Florida Atlantic University, 2018.

[6] J. Meyer, "Evaluating action research," British Geriatrics Society, 2000.

[7] S. Khan and P. Tzortzopoulos, "An evaluation framework for an action research study on lean design management," Proc. 24th Ann. Conf. of the Int'l. Group for Lean Construction. Boston, sect. 1, pp. 113-122, 2016.

[8] L. Rowell, E. Pollush, M. Riel, and A. Bruewe, "Action researchers' perspectives about the distinguishing characteristics of action research: A delphi and learning circles mixed-methods study," Educational Action Research, vol. 23, no. 2, pp. 243-270, 2015.

[9] M. Morales, E. Abulon, P. Soriano, A. David, M. Hermosisima, and M. Gerundio, "Examining teachers' conception of and needs on action research," Issues in Educational Research, vol. 26, no. 3, pp. 464-489, 2016. 
[10] O. Skeritt and M. Fletcher, "The quality of an action research thesis in the social sciences," Quality Assurance in Education, vol. 15, no. 4, pp. 413-436, 2007.

[11] R. Hummel, "Exploring action research as an enduring experience of professional development for teachers," Fielding Graduate University, ProQuest Dissertations Publishing, 2017.

[12] A. Feldman, "Validity and quality in action research," Educational Action Research, vol. 15, no. 1, pp. 21-32, 2007.

[13] M. Sahin and H. Yurdugul, "A content analysis study on the use of analytic hierarchy process in educational studies," Journal of Measurement and Evaluation in Education and Psychology, vol. 9, no. 4, pp. 376-392, 2018.

[14] J. Creswell, Educational research: Planning, conducting, and evaluating quantitative and qualitative research. Pearson. Fourth edition, 2014.

[15] R. Vargas, "Using the analytic hierarchy process (ahp) to select and prioritize projects in a portfolio," PMI Global Congress 2010 - North America, Washington, DC. Newtown Square, PA: Project Management Institute, 2010.

[16] Y. Jusoh, K. Chamili, N. Pa, and J. Yahaya, "Open source software selection using an analytical hierarchy process (AHP)," American Journal of Software Engineering and Applications, vol. 3, no. 6, pp. 83-89, 2014

[17] R. Velmurugan, S. Selvamuthukumar, and R. Manavalan, "Multi criteria decision making to select the suitable method for thepreparation of nanoparticles using an analytical hierarchy process," 2001.

[18] A. Yadav and S. Jayswal, "Using geometric mean method of analytical hierarchy process for decision making in functional layout," International Journal of Engineering Research \& Technology, vol. 2, no. 10, pp. 775-779, 2013.

[19] H. Bradburry-Huang, "Quality in action research," Available: Academia, 2015.

[20] R. Deery, "Balancing research and action in turbulent times: Action research as a tool for change," The Royal College of Midwives. Evidence Based Midwifery, vol. 9, no. 3, pp. 89-94, 2011.

[21] K. Frogatt and J. Hockley, "Action research in palliative care: Defining an evaluation methodology," Palliative Medicine,vol. 25, no. 8, pp. 782-787, 2011.

[22] C. Bissessar, "Research to praxis: Empowering Trinidadian primary school teachers via action research," Australian Journal of Teacher Education, vol. 40, no. 9, pp. 176-192, 2015.

[23] J. Robertson, "The three Rs of action research methodology: Reciprocity, reflexivity and reflection-on-reality," Educational Action Research, vol. 8, no. 2, pp. 307-326, 2000.

[24] G. Hine, "The importance of action research in teacher education programs," Issues in Educational Research, vol. 23, no. 2, pp. 151-163, 2013.

[25] M. Caliskan and H. Serce, "Action research articles on education in Turkey: A content analysis," Journal of Kirsehir Education Faculty, vol. 19, no. 1, pp. 80-102, 2019.

[26] B. Chisaka and M. Mukabeta, "Action research and educational practice," Save the Children, pp. 1-54, 2013.

[27] B. Guy, T. Feldman, C. Cain, L. Leesman, and C. Hood, "Defining and navigating 'action' in a participatory action research project," Educational Action Research, vol. 28, no. 1, pp. 142-153, 2020.

[28] C. Hong and S. Lawrence, "Action research in teacher education. Classroom inquiry, reflection, and data-driven decision making," Journal of Inquiry \& Action in Education, vol. 4, no. 2, pp. 1-16, 2011.

[29] M. Amin, R. Rashid, and K. Teh, "Investigating issues and challenges in emlpoying action research for teacher training in Malaysian context," International Journal of Education and Practice, vol. 7, no. 1, pp. 30-40, 2019.

[30] J. Luttenburg, P. Meijer, and H. Marchan, "Understanding the complexity of teacher reflection in action research," Educational Action Research, vol. 25, no. 1, pp. 88-102, 2017.

[31] Q. Zhang and C. Amundsen, "Exploring the experiences of faculty-led teams in conducting action research," The Canadian Journal for the Scholarship of Teaching and Learning, vol. 6, no. 1, pp. 1-18, 2015. 